\title{
Development of an Instructional Model with Augmented Reality Technology for Vocational Certificate Students
}

\section{Theeraphant Pipattanasuk}

$\mathrm{Ph}$.D. candidate, Division of Learning Innovation and Technology, Faculty of Industrial Education and Technology, King Mongkut's University of Technology Thonburi, Bangkok, Thailand, theeraphant.bump@mail.kmutt.ac.th

\author{
Alisa Songsriwittaya \\ Assoc. Prof., Division of Learning Innovation and Technology, Faculty of Industrial \\ Education and Technology, King Mongkut's University of Technology Thonburi, \\ Bangkok, Thailand, alisa.son@kmutt.ac.th
}

The purposes for this research were to design and develop an instructional model using augmented reality technology for vocational certificate students, then evaluate the efficiency of the model, and finally evaluate the samples' satisfaction toward the model. The sample group were thirty third-year students from a vocational college in the northeast region in Thailand, who enrolled in microcontroller foundation course in the second semester of academic year 2019. The sample group were selected by simple random sampling method and then divided into two groups as experiment group and control group, consisted of fifteen students in each group. The research tools comprised of 1) the instructional model with augmented reality technology, and 2) the learning achievement test. The research results found that the instructional model consisted of six steps called ISDEEE; Information, Searching, Discussion, Explanation, Experiment and Evolution. The efficiency of the model was 84.22/83.86, which was higher than the expected standard 80/80. The learning achievements of the students in the experiment group after using the model were significant higher than the control group at .05 level. The students' satisfaction toward the instructional model was also at a high level. Therefore, it could be concluded that the instructional model using augmented reality technology had efficiency and suitable to apply to the microcontroller foundation course for vocational certificate students.

Keywords: augmented reality technology, vocational education, ISDEEE model, instructional model, microcontroller foundation course

Citation: Pipattanasuk, T., \& Songsriwittaya, A. (2020). Development of an Instructional Model with Augmented Reality Technology for Vocational Certificate Students. International Journal of Instruction, 13(3), 539-554. https://doi.org/10.29333/iji.2020.13337a 


\section{INTRODUCTION}

The educational system in 21 st century has a tendency of student-centred learning model by building motivation in order to create a self-sustainable and a more significant learning. Therefore, the effort of today involves integrating the use of technology in educational system (Fedynich, 2013). Teachers place important on technology based education in class, such as student-centred education, technology based education, handon training, lab-based education and e-Learning. The result shows that students can engage more when they can control flow of their experience, or when their learning is self-directed (Jaleel \& Anuroofa, 2017). The continuous development of cyberspace helps in producing new and modern educational media. Multimedia is one of the popular tools among teachers, especially Augmented Reality (AR). This technology superimposes a computer-generated image on a user's view of the real world via mobile device such as a smartphone or tablet with a digital software and then providing a 3Ds composite view or 360 degree panorama. The advantage of AR multimedia features a definite impression to students, which resulting in an enjoyable environment and comprehension in class. Hence, the augmented reality technology indeed plays an important role in learning environment and educational system. It can provide a more approachable and easier access to learning sources in both group and individual study (Lee, 2012).

In addition, the benefits of rapid development of technology and the anytime anywhere learning style, the Vocational Education Commission acknowledges the importance of technology in order to enhance students' knowledge and skills. The technology integrated learning policy has become one of the most important policies to promote an effective vocational education system. The process is to create the self-access learning center in every vocational institutes (Bureau of Vocational Education Standards and Qualifications, 2012). The advantage of information technology is to enhance students' life-long learning skills. Dixon (1992) stated that self-access learning center was one of the keys to live in society efficiently. It is the best way to enhance ability in self-directed learning that learners always learn things habitually, including initiate their own learning to the complete process. (Knowles, 1975). Self-access learning can be done at the appropriate time according to the students' convenience and flexibility (Spiro, 1991).

Microcontrollers Foundation course is currently one of a significant course as it is corresponding with the development of the controller and embedded system. The Vocational Education Commission, thus assigned the Microcontrollers Foundation course in the Electrical Power Program, which will enhance students' knowledge and skills to work in industrial factory professionally. However, the survey data from teachers and students in several vocational institutes found that students are lack of understanding in microcontroller foundation concepts and they cannot apply knowledge to practice. The problems also stated that most teaching method was lecture based, and the activity in class was only question and answer. Therefore, most students were misunderstand to the microcontrollers circuit and the instant sample which came in a large number caused them to spend more time than expected in the experiments. Moreover, it further affected the experimental worksheets and so on which lead to the 
significantly low academic achievement resulting in the occupation in the industry (Ming-Puu and A.H.G. Al-Dhaher,.... ). The problem is the performance environment, such as the lack of tools, lack of actual training opportunity, lack of quality media to enhance problem - solving skills, lack of conceptualization ability, lack of problem solving process and hand - on activity experiences. Most of the students lack of interest and enthusiasm in the learning because the program requires complicated calculation skills and it is not a student-centred learning system., which leads to the significantly low academic achievement. The main issue is to investigate the new instructional model integrated with technology.

The design of instructional system in 21 st century requires a student - centered rather than a teacher - centered learning model (constructivism), by having students collect, research, analyze and synthesize the information. These learning models, inquiry learning, problem-based learning (Ruengrong et al., 2014). Conform to Helms et al. (... ) stating that the learning model that building a motivation is the one that the learners enjoy with. The academic activities can be designed to help with the students' encouragement as follows; applying game strategy, utilizing special presentation technique, creating student's choices, or making lessons and activities interactive to stimulate the students' curiosity.

\section{The Research Objectives}

To develop and design the student-centered learning model with augmented reality technology for vocational certificate students.

\section{LITERATURE REVIEW}

\section{Self - Directed Learning (SDL) Concept}

Gibbons (2002) describes 'SDL is a process that occurs naturally for everyone. Self directed learning is an essential skill required in the 21 st century educational world', self-directed learning is a widely recognized type of learning to meet mandatory continuing professional education requirements (Curran et al., 2019). conforming to Knowles (1975) describes 'SDL is a process in which individuals take the initiative, with or without the help of others, in diagnosing their learning needs, formulating their learning goals, identifying human and material resources for learning, choosing and implementing appropriate learning strategies, and evaluating learning outcomes'. In order to promote SDL, teacher and students, together, are required to create a pleasant learning environment including accepting and respecting each other. Teacher is to accept student that is open - minded and willing to learn, vice versa, student is to accept teacher's experience and advice to create SDL leading to trust and reliance. Students are to concern about their learning needs lucidly in order to identify their resources for learning and implement further learning strategies.

The development of students to be self - directed learners is beneficially applied in this modern times where everyone can easily access to the material resources for learning and be able to independently develop oneself and gain more understanding and 
knowledge to develop the profession according to the quality demand of the labour market these days.

\section{Augmented Reality (AR) Technology Concept}

Augmented reality technology is a technology that superimposes a computer - generated image on a user's view of the real world, thus providing a composite view (Graham et al., 2013). AR is a technology with vast potential and great pedagogical that offers new methods for the purpose of education (Izwan et al., 2018). It supports the user's perception by adding the audio and graphic video onto device screen such as smartphone and tablet (Bottani \& Vignali, 2019). Hence, user will see the computergenerated image of the real world on the screen. For example, when looking at a textbook through the device, user will see the graphic image of an elephant walking on the textbook and hear its sound from the device, but once the textbook is away from the device, the image and the sound disappear. Crofton, Botinestean, Fenelon, and Gallagher (2019) stated that AR is very useful for interactive and real learning media for students. AR can visualize abstract concepts for understanding and structure of an object model (Lindner et al., 2019).

The mention learning model promotes self - directed learning, pleasure and motivation according to the study by Moore and Atkin (2012), found that learning through the tablet device has the advantage of attractiveness and motivation. AR is new teaching and learning models that better meet the needs of the 21st century learner (Elmqaddem, 2019).

The study of the use of augmented reality technology in education found that students' ability to experience and learn have improved comparing to the traditional learning model (Yeom, 2011). The virtual reality technology plays important role in learning model with its potential to transform the complicated information into a simple concept via images and human senses expanding the knowledge and learning experience. Applying virtual reality technology as a teacher's tool, illustration and worksheet has a positive impact to the learning increasing student's interest in science (Shelton\& Hedley, 2002). AR can influence students' problem solving skills, motivation, and learning outcomes (Astuti et al., 2019). As stated by Oranç and Küntay (2019) the development of AR learning can support the students' learning.

Therefore, AR technology is definitely helpful to students' development in terms of an instant interaction in the real world.

\section{METHOD}

\section{Sample of the Research}

The sample group in this research were thirty third-year students from a vocational college in the northeast of Thailand, who enrolled in Microcontrollers Foundation course in the second semester of academic year 2019. The sample group were selected by using simple random sampling method and then divided into two groups as experiment group and control group, consisted of fifteen students in each group. 


\section{Instrument and Procedures}

The objective of this research is to design and develop an instructional model using augmented reality technology and to invent the educational media for Input and Output Control in Microcontrollers Foundation Course. The development of new learning model and the instructional package with innovative media are featured in this program, as shown in Figure 1.

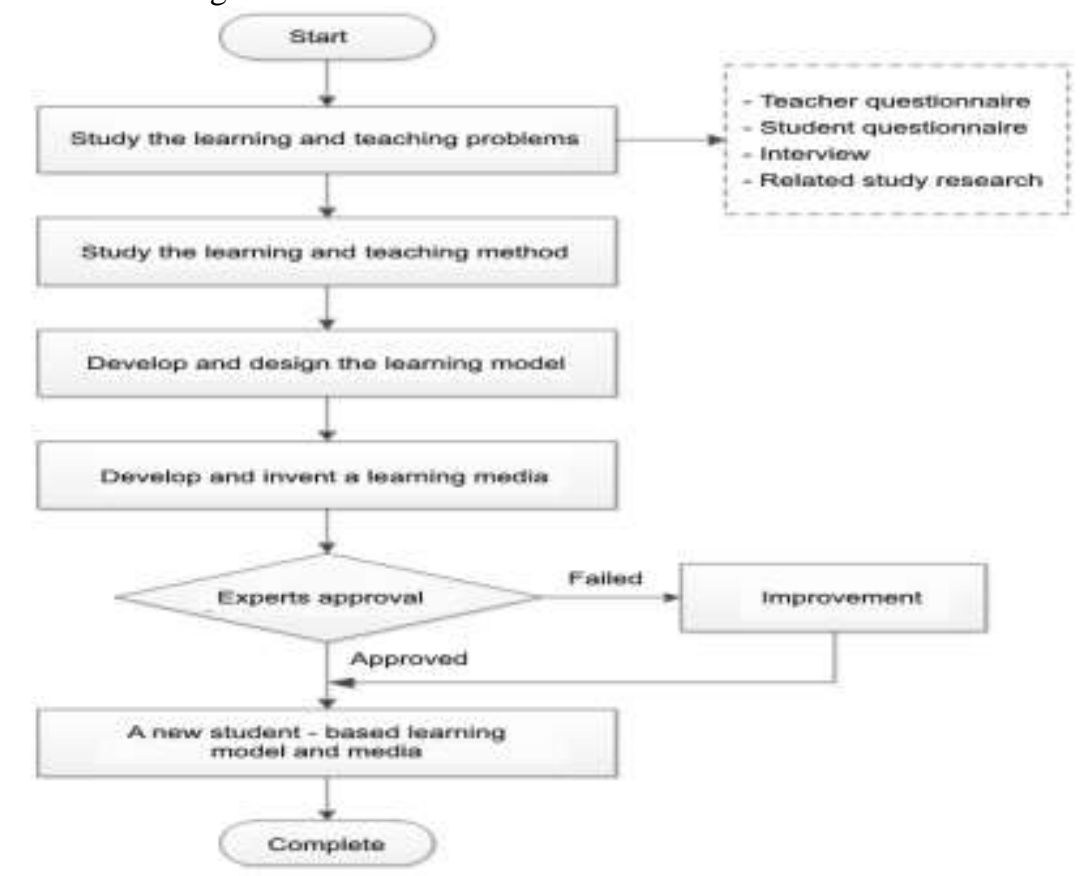

Figure 1

The Design and Development Process of the Instructional Model

Step 1: The study of the learning and teaching problems in Microcontrollers Foundation course

The questionnaire was used as a mean to collect the learning and teaching management problems in Microcontrollers course from the teachers and students who enrolled in this course in the second semester of academic year 2018. It could be concluded that the main problem was the learning model. The traditional learning model, where specific procedure worksheets were provided, teaching methods were lecture based, and using question and answer, power point and board presentation as a main media. That was leaded to the lack of students' activity to help promoting further self - knowledge and self - motivation which impacts the understanding of the experiments and absolute performance objectives. 
Step 2: The design and development of Microcontrollers Foundation course learning teaching model for the certificate vocational students

The design and development of Microcontrollers Foundation Course learning - teaching model for certificate vocational students follows the student-centred learning system concerning the suitability of the model management and student's individual nature differences such as intelligence, personality, creativity and other behaviour. The teaching method, thus, aims to provide an acquisition of knowledge in understanding, skilfulness, along with attitude. This will highly allow students to be part of the learning and teaching process when they can determine the self - learning performance while the teacher is there to assist, support, advise and accommodating to help students achieve the goals.

The development of the learning and teaching model

The development of the student-centred learning model is a theoretical teaching of selfdirected learning process by having students encounter the problem that causes intellectual conflict. The students are to come up with a solution or take a careful action in order to achieve a new problem - solving intellectual structure, which requires a concept idea and creativity integrated with modern technology and proper media to build a concrete knowledge. Hence, this learning model methodology depends on the student's behaviour development from the basic to the expected level. It will also help students to build a cognitive ability in order to achieve the learning objectives effectively.

Researcher has studied the student-centred learning model as follows;

1. Problem-based learning (PBL) is a student-centred pedagogy in which students learn about a subject through the experience of solving an open-ended problem found in trigger material under the supervision of teacher.

2. Individual study dues to the student's individual differences in learning ability and interest requiring various strategies such as,

2.1 Concept mapping technique examining the student's idea of the lesson understanding and shown in illustrated diagram

2.2 Learning contract technique identifying an appropriate learning strategies between the teacher and learner

2.3 Know-Want-Learned technique having students brainstorming everything they know about a topic using mapping such as a class presentation from student's research and an audience test afterwards

2.4 Group process technique allowing collaboration between students to exchange their idea and knowledge in order to solve the problems and achieve the common goals

3. Constructivism is based on the belief that learning occurs as learners are actively involved in a process of meaning and knowledge construction as opposed to passively receiving information. Learners are the makers of meaning and knowledge. 
4. Self - study involves students conducting a self - directed learning, such as inquiry instruction, discovery learning, problem solving and experiential learning, which can be applied in both individuals and groups.

5. Worked - based learning is an educational strategy that provides students with reallife work experiences where they can apply academic and technical skills and develop their employability.

The student-centred learning models mentioned above can be integrated together in order to conduct the Microcontroller Foundation course. Researcher has designed a student-centred learning activities by using the hands-on task in an actual situation, formulated creativity procedure, systematically operation, self-intellectual, problem solving solution and data analysis, which help students to develop overall skill and capability, comprising of 6 steps as shown in Figure 2 as follows,

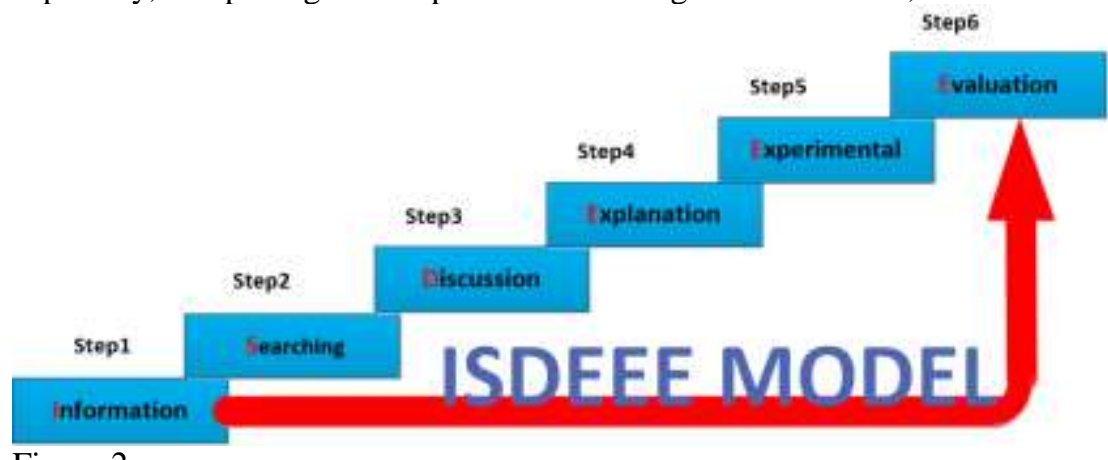

Figure 2

ISDEE Learning Model

Step 1: Information: Teacher will provide the lesson plan, process and activity including the learning materials and instruments. Student will study the subject according to the teacher assignment and the use of materials and instruments for learning.

Step 2: Searching: Student independently conducts the knowledge from various resources in order to collect the related information for the next step. Teacher will assist and advise the student in all sorts. Student will explore the problem solving solution by applying the theoretical intellectual as a reference or examining the result using a mock up program.

Step 3: Discussion: The result of the research will be discussed in this stage to provide the abstract notion and concept to audience, which helps promoting intellectual exchange between student and student or student and teacher leading to an accurate and systematic conclusion.

Step 4: Explanation: Teacher makes a clear summary of the principle, theory or brief content including analysing, interpreting and concluding the result for student. Teacher also raises an issue in this stage to draw student's attention to produce evidence in the next stage. Teacher and student will monitor the comprehension together so that student can intellectually conclude the subject. 
Step 5: Experimental: Students perform task together in group according to the learning activity using the designed multimedia and later collect data, analyse and sum up the experiments result under the supervision of the teacher following the assigned procedure.

Step 6: Teacher and student evaluate students' performances together for the feedbacks which will be useful for further experiment task, such as instrumental usage, elaboration, memorandum, report presentation and experiments group collaboration.

From the related theory and survey as mentioned above, researcher has applied to the learning model development and design by having students engage in most part of the process according to the student - based learning system concerning individuals differences which will help creating a lifelong learning skill and promoting a constructionism.

2.2 The design development of the AR Technology teaching media and the

Microcontrollers Foundation technical lessons

Researcher has analyzed the course syllabus and description to identify the subject matters in order to create field training lessons and the behavioral objectives of each subject. The training lessons for Microcontrollers Foundation course will be created according to the model and approved by 10 experts, 5 technology education experts and 5 electrical engineering and electronics experts, which will later be adjusted and rectified before applying to the representative sample group in order to find the efficiency of the model.

There are 3 steps to create a augmented reality technology media in

Microcontrollers Foundation Program,

1. The design development of 3Ds model: SketchUp is the main tool to design and develop the 3Ds instrument models showing the sample of LED (see Figure 3)

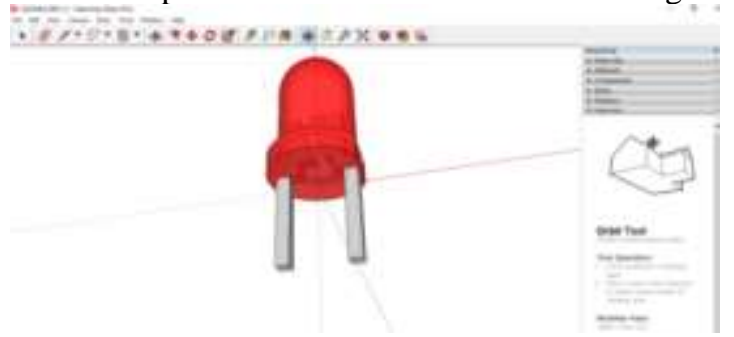

Figure 3

The Design Development of 3Ds Model using Sketch Up

2. The development of android application: PixLive Maker is an instant software to help creating augmented reality technology media. It can read the marker value via the camera and display a corresponding 3Ds model, as shown in Figure 4 


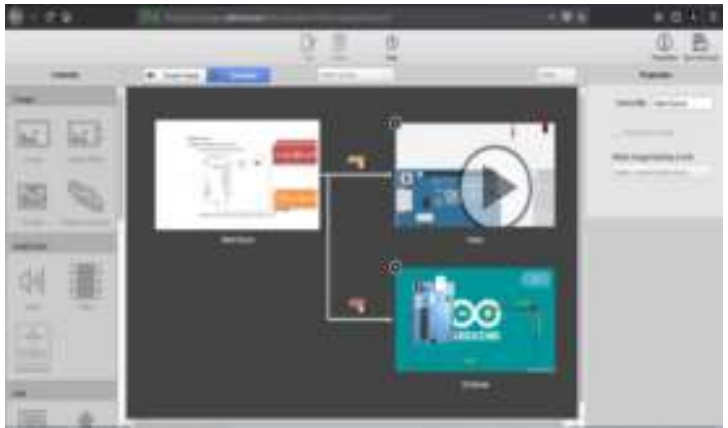

Figure 4

The Development of Android Application using PixLive Maker

The result of the development of augmented reality technology media includes 3Ds images, 3Ds circuit connection, subject contents and exercises, as shown in Figure 5
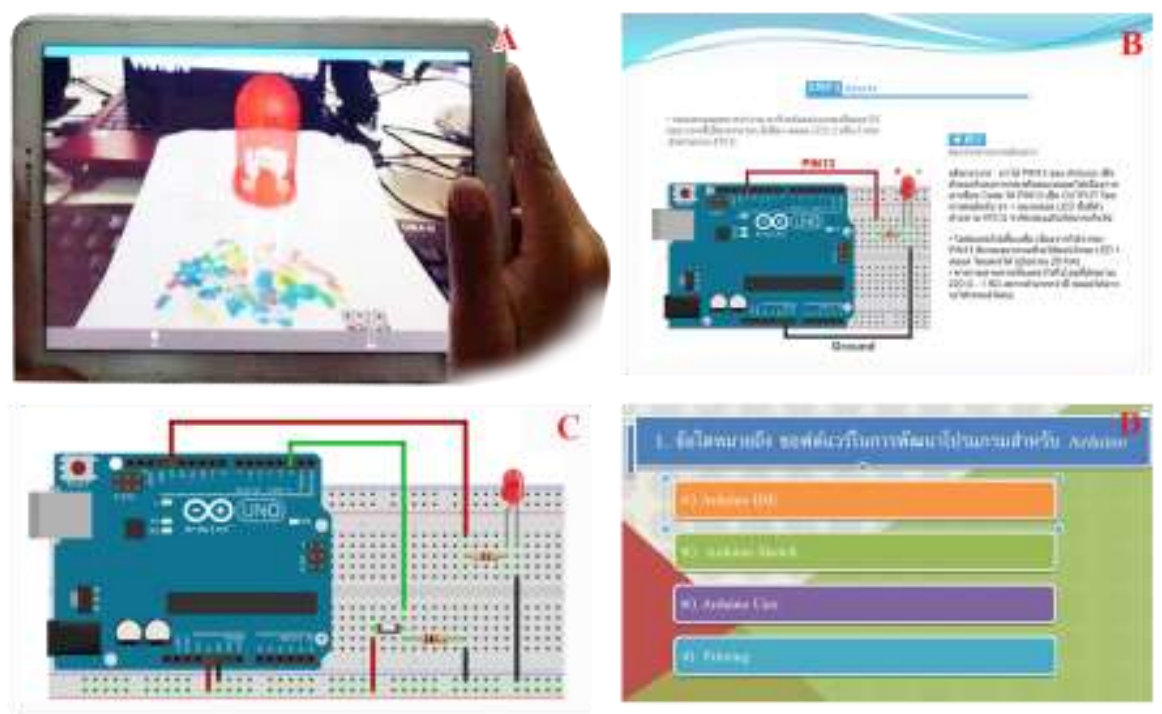

Figure 5

(A) 3Ds Images (B) Subject Contents (C) 3Ds Circuit Connection (D) Exercises

Step 3 The experimental study of efficiency and achievement of Microcontrollers Foundation for Certified Vocational Students learning model

The developed learning model has been examined its efficiency to the $80 / 80$ standard by having 67 representative vocational certificate students in their third year from one of a college in northeast region who enrolled in Microcontrollers Foundation in Electrical Mechanics Program, first semester 2017 academic year, tested on the basic training knowledge. The simple random sampling method was employed for 3 times, from the 42 
representative students with training scores less than $60 \%$. The first one is on 3 students with different ability level - excellent, fair and poor, to examine the basic quality in lessons understanding, presentation method and field training procedure using observation and interview method to collect the feedback for further improvement. The second one is on 9 students with different ability level - excellent, fair and poor, with the same method to the field training in order to find the tendency of Microcontrollers Foundation lessons efficiency and examine some errors for further improvement. The third one is on 30 students with different ability level - excellent, fair and poor, in order to find the efficiency of Microcontrollers Foundation learning model for certified vocational students after theoretical lessons and a post - examination in each unit. In the meantime, students in field training section practice over the procedure to improve their technical skills while teacher examining the students' works in each process using training skill range evaluation for (E1) value. After students complete the lessons in every units, they are required for the post - examination and field training test using the training skill range evaluation for efficiency value (E2).

After the qualified and efficient learning model of Microcontrollers Foundation for Certified Vocational Students, 38 representative vocational certificate students in their third year from one of a college in northeast region who enrolled in Microcontrollers Foundation in Electrical Mechanics Program, second semester 2017 academic year, has been tested on the basic training knowledge. The simple random sampling method was employed, having 30 representative students dividing into 2 groups of 15 comparing their academic achievement between those with the developed learning model with AR technology to those with the traditional learning model. The students are required to take pre - examination in each unit and perform experiments according to the procedure, in order to study students' satisfaction. The process took place in 4 hours per day per week for a total of 4 weeks, including post - examination and a questionnaire of satisfaction to Microcontrollers Foundation learning model for Certified Vocation Students. The information collected in this process will further be analyzed in the next step.

\section{Data Analysis}

This research used the following method of analysis. First, the mean and standard deviation were calculated to quality evaluation of Instructional Model with Augmented Reality Technology. And second, t-test was conducted to examine the difference of student achievement between those who learn with the developed of instructional model with augmented reality technology and those who learn in traditional style.

\section{FINDINGS}

1. The result of the quality evaluation of Instructional Model with Augmented Reality Technology for Certified Vocational Students.

Learning model evaluated by Electronics experts and media producer experts, the result of the quality of Microcontrollers Foundation learning model is evaluated as shown in Table 1. 
Table 1

The Quality Evaluation of Instructional Model with Augmented Reality Technology by Experts

\begin{tabular}{lccl}
\hline & \multicolumn{2}{l}{ Critique Rate } & \\
\hline Questions & $\overline{\boldsymbol{X}}$ & S.D. & Value Translation \\
\hline 1. Learning Model & 4.31 & 0.14 & High \\
\hline 2. Learning Media (Augmented Reality Technology) & 4.17 & 0.05 & High \\
\hline 3. Worksheet & 4.17 & 0.13 & High \\
\hline 4. Evaluation & 4.25 & 0.09 & High \\
\hline Overall Mean Value & 4.22 & 0.10 & High \\
\hline
\end{tabular}

From Table 1, the overall quality of the Instructional Model with Augmented Reality Technology has a high level of propriety at the mean value of 4.22, standard deviation of 0.10 . It is found that the mean value in every aspects is at high level. The highest mean value goes to Learning Model at 4.31, following by the Worksheet and Learning Media at both 4.17. The lowest mean value goes to Evalution at 4.17.

\section{The efficiency of the Microcontrollers Laboratory Set}

The marks were accumulated by having students take tests during the training process and later a post - examination once they completed all the lessons. The final marks are analyzed to find the learning model efficiency (E1/E2), as shown in Table 2

Table 2

Efficacy of the Instructional Model with Augmented Reality Technology According to the Criteria of the Efficacy 80/80

\begin{tabular}{lccc}
\hline Worksheets & Full Marks & Mean Value & Effective Value \\
\hline Marks from exercises / worksheets & & & \\
Worksheet 1 & 50 & 41.66 & 83.33 \\
Worksheet 2 & 50 & 42.55 & 85.11 \\
\hline E1 & 100 & 42.10 & 84.22 \\
\hline Marks from exercises / worksheets & & & \\
Worksheet 1 & 50 & 41.73 & 83.46 \\
Worksheet 2 & 50 & 42.13 & 84.26 \\
\hline E2 & 100 & 41.93 & 83.86 \\
\hline
\end{tabular}

From Table 2, the percentage of the efficiency of the Instructional Model with Augmented Reality Technology, representative sample, marks from exercises and worksheets during the training (Worksheet 1-2) is 84.22 percent. The percentage of when students completed the lessons and practice over the course, post - examination and post - performance skill test (Worksheet 1-2) is 83.86 percent. Thus, the percentage of the efficiency of Microcontrollers Foundation laboratory set integrated with virtual reality technology is $84.22 / 83.86$ percent higher than the expected standard 80/80.

\section{Comparison of academic achievement between the Instructional Model with Augmented Reality Technology and the traditional learning model}

Completed every educational units, researcher evaluated the academic achievement of the representative samples using the academic achievement test in order to compare the 
achievement result between the representative samples and the conducted group with the statistical significance at .05 as shown in Table 3.

Table 3

Academic Achievement Value Comparison between the Representative Samples and the Conducted Group

\begin{tabular}{lllllll}
\hline Group & N & Full Marks & X & S.D. & t-test & P-Value \\
\hline \multirow{2}{*}{ Sample Conducted } & 15 & 100 & 83.86 & 1.76 & \multirow{2}{*}{5.051} & \multirow{2}{*}{$.000^{*}$} \\
& 15 & 100 & 77.86 & 2.12 & & \\
\hline
\end{tabular}

$* \mathrm{P}<0.05$

From Table 3, the academic achievement of the students with the new learning model and developed laboratory set is significantly higher than those with the traditional learning model at the .05 level.

\section{Students' satisfaction over the Instructional Model with Augmented Reality Technology}

The objectives of this evaluation of the representative samples' satisfaction is to study the satisfaction over the learning system using in Microcontrollers Foundation Program. The satisfaction result is shown in Table 4.

Table 4

Evaluation of the Representative Samples' Satisfaction Over the Instructional Model with Augmented Reality Technology

\begin{tabular}{lccl}
\hline & \multicolumn{3}{l}{ Critique Rate } \\
\cline { 2 - 4 } Questions & $\overline{\boldsymbol{X}}$ & S.D. & Value Translation \\
\hline 1. Learning Model & 4.25 & 0.09 & High \\
\hline 2. Learning Media (Augmented Reality Technology) & 4.40 & 0.05 & High \\
\hline 3. Worksheet & 4.40 & 0.09 & High \\
\hline 4. Evaluation & 4.31 & 0.02 & High \\
\hline Overall Mean Value & 4.34 & 0.06 & High \\
\hline
\end{tabular}

From Table 4, the overall students' satisfaction over the Microcontrollers Foundation learning model is very high with the mean value of 4.34 and the standard deviation of 0.06 Considering all the factors, the mean value in every topics is at high level. The highest mean value goes to Worksheet and Learning Media at both 4.40. following by the Evaluation at 4.31. The lowest mean value goes to Learning Model at 4.25.

\section{DISCUSSION}

The result of this research found that The efficiency evaluation of instructional model with augmented reality technology for certified vocational students is at the expected standard due to the fact that this learning model promotes teamwork environment where students can support each other have those with a more comprehension passing on subject matters, thus the colleagues can as well easily understand the lessons. Unlike the traditional teaching method, the mentioned teaching method will also encourage students to speak up and express their opinions in class without being afraid of making mistakes, according to Martin and team. The attempt in self - directed learning and 
constructionism will enhance students' comprehension profoundly. according to Martin and team found that the attempt in self - directed learning and constructionism will enhance students' comprehension profoundly (Martin et al., 1990)

The efficiency percentage of instructional model with augmented reality technology is 84.22 / 83.88 percent, which is according to the expected standard 80/80 and the study hypothesis. Due to the well - prepared materials and well - planning process, such as course syllabus analysis, a study from another researches and their works, and the learning instruments suitable with the experiments quality - approved by the academic content experts, the course essence covers all the necessary practical skills according to the learning objectives. The laboratory set design follows the principle of the self directed learning psychology focusing on hands - on tasks, including its attractive features and compact size according to the study by Chanin Nhurid (2016), found that the students' satisfaction after the Mechanical Power Technology and Theory course using augmented reality technology as a media on android system smartphone, is very high due to its ability to display a realistic and interesting motion picture of the model according to the subject matters encouraging the representative samples' motivation in learning as seen in the pleasant environment observation in class.

The academic achievement comparison between the instructional model with Augmented Reality technology and the traditional one, found that students who take instructional model with Augmented Reality technology have a significantly higher achievement at the .05 level, due to the fact that learning media plays an important role in passing on the information from both teacher and learning resources to students. It acts as a center source of students' interest making the lessons more remarkable and a concrete tool to support teamwork. Students can see and experience through the real situation according to the study by Meek (1972). Comparing the hands-on teaching method to the traditional one, found that the efficiency of the hands-on one is significantly higher than the traditional one at the 0.01 level. The students in the AR experimental group had higher learning achievement than the students in the control group. (Shiue et al., 2019)

The result of students' satisfaction to the instructional model with Augmented Reality technology is very high due to the fact that the instructional package is a modern technology popular among the students generation with its text, graphic picture, colorful motion, soundtrack and audio making them enjoy the lessons and meet individuals' needs of learning ability as students can rewind the contents if they want to re-study. The students' satisfaction to the learning model is according to a study by Promboon stating that having students perform tasks themselves, exchange their idea as a teamwork and responsible for their own duty, allow them to envision the importance of their role and the team's, thus the students' satisfaction over this student - based learning model is overall at a high level (Promboon et al., 1997). According to a study by Heather found high levels of student satisfaction for VR/AR teaching methods. It can be observed that VR/AR had a notable impact on spatial understanding, motivation and interest. Other reported areas of benefit included autonomous learning, confidence, cognitive load and overall student perceptions (Heather et al., 2019). 


\section{CONCLUSION}

In this research, we presented a development of instructional model with Augmented Reality technology for hands-on practical laboratory experiments for vocational certificate students. The implementation approach focuses on the use of mobile devices (smart-phones/tablets) as AR platforms. Using augmented reality in the classroom can turn an ordinary class into an engaging experience. AR technology provides virtual examples and adds gaming elements to support textbook materials. As a result, classes become more interactive. AR helps students better remember the information they've just learned.

\section{IMPLICATIONS}

$\mathrm{AR}$ is an interesting and recent technology which can provide the learners with new experiences. Integration of real world and virtual world can be used in teaching the generic skill which might be difficult for lower proficiency learners. The AR technology can also help teachers to explain the content clearly and make the students easily understand the concept. The use of AR technology has also received positive feedback from participants and students who have shown their interest in using AR in their learning processes. These good responses are important because they indicate the willingness of students to actively engage in their learning through AR tools.

\section{LIMITATIONS OF THE STUDY}

Although AR technology is used widely in teaching and learning process due to its' advantages, this technology requires so many facilities to process. It is not easy to implement AR technology in classroom setting because the lack of facility such as highspeed internet connection and insufficient mobile devices. Thus, the educational policy that will use AR technology in the institute should provide budget for installing the facility as well.

\section{SUGGESTIONS FOR FURTHER STUDY}

This instructional model with AR technology can use as a prototype for another subject. Furthermore, we can apply AR technology with other instructional models, for example, cooperation learning, detective learning and research-based learning, to improve students' motivation to learn that will lead to expected learning outcome.

\section{REFERENCES}

Al-Dhaher, A.H.G. (2001). Integrating hardware and software for the development of microcontroller based systems. J of Microprocessors and Microsystems, 25(7), 317-328

Amelink, C., Scales, G., \& Tront, J. (2012). Student use of the tablet PC: Impact on student learning behaviors. Advances in Engineering Education, 3, 1-17.

Astuti, F. N., Suranto, S., \& Masykuri, M. (2019). Augmented reality for teaching science: Students' problem solving skill, motivation, and learning outcomes. JPBI (Jurnal Pendidikan Biologi Indonesia), 5(2), 305-312. 
Bottani, E., \& Vignali, G. (2019) Augmented reality technology in the manufacturing industry: A review of the last decade, IISE Transactions, 51(3), 284-310

Chanin, N. (2016). Development of learning media with augmented reality technology on automotive calculation and theory subject (Unpublished master thesis). Faculty of Industrial Education King Mongkut's University of Technology North Bangkok.

Crofton, E. C., Botinestean, C., Fenelon, M., \& Gallagher, E. (2019). Potential applications for virtual and augmented reality technologies in sensory science. Innovative Food Science \& Emerging Technologies, 56, 102178.

Curran, V., Gustafson, DL., Simmons, K., Lannon, H., Wang, C., Garmsiri, M., Fleet, L., \& Wetsch, L. (2019) Adult learners' perceptions of self-directed learning and digital technology usage in continuing professional education: An update for the digital age. Journal of Adult and Continuing Education, 25(1), 74-93

Dixon, W.B. (1992). An exploratory study of self-directed learning readiness and pedagogical expectations about learning adult inmate learners in Michigan (Unpublished doctoral dissertation). Michigan State University, USA.

Elmqaddem, N. (2019). Augmented reality and virtual reality in education. myth or reality? Int Journal of Emerging Technologies in Learning (IJET), 14(3), 234-242.

Fedynich, L. (2014). Teaching beyond the classroom walls: The pros and cons of cyber learning. Journal of Instructional Pedagogies, 13, 1-7.

Gibbons, M. (2002). The self-directed learning handbook: Challenging adolescent students to excel. San Francisco, CA: Jossey-Bass.

Graham M., Zook M., \& Boulton, A. (2013). Augmented reality in urban places: contested content and the duplicity of code. Transactions of the Institute of British Geographers, 38, 464-79.

Heather, A., Chinnah, T., \& Devaraj, V. (2019). The use of virtual and augmented reality in anatomy teaching. MedEdPublish, 8(2), 7, https://doi.org/10.15694/mep.2019.000077.1.

Ivanitskaya, L., Clark, D., Montgomery, G., \& Primeau, R. (2002). Interdisciplinary learning: Process and outcomes. Innovative Higher Education, 27(2), 95-111.

Izwan, N. M. B., Syed, Z. S. I., \& Salleh, A. R. (2018). The use of augmented reality technology for primary school education in Perlis, Malaysia. Journal of Physics Conference Series, 1019(1), 1-9

Khan, T., Johnston, K., \& Ophoff, J. (2019). The impact of an augmented reality application on learning motivation of students. Advances in Human-Computer Interaction, 2, 1-14.

Knowles, M. S. (1975). Self-directed learning: A guide for learners and teachers. Chicago: Follett Publishing Company.

Lee. K. (2012). Augmented reality in education and training. Tech Trends, 56(2), 13-21. 
Lindner, C., Rienow, A., \& Jürgens, C. (2019). Augmented reality applications as digital experiments for education-An example in the earth-moon system. Acta Astronautica, $161,66-74$.

Martin, R. E., Jr, Sexton, C., Wagner, K., \& Gerlovich, J. (1994). Teaching science for all children. Massachusetts: Allyn and Bacon.

Meeks, E. B. (1972). Learning packages versus conventional methods of instruction. (Unpublished doctoral dissertation). Iowa State University.

Chen, M. P., Chiu, C. H., \& Wu, C. C. (2010). Instructional simulations for teaching high school computer science concepts: A technology acceptance perspective.in IEEE International Conference on Digital Game and Intelligent Toy Enhanced Learning, 216-218.

Moore, J., \& Atkin, C. (2012). An application (app) for learning - the student interface with tablet technology in graduate studies. Proceedings of the European Conference on e-Government, 328-35

Office of the Vocational Education Commission. (2008). Vocational Education Act B.E. 2551. Retrieved from http://www.vec.go.th/Portals/0/Doc/Low/vec_law_2.pdf.

Oranç, C., \& Küntay, A. C. (2019). Learning from the real and the virtual worlds: Educational use of Augmented Reality in early childhood. International Journal of Child-Computer Interaction, 21, 104-111.

Onime, C., \& Abiona, O. (2016) 3D mobile augmented reality interface for laboratory experiments. Int J of Communications, Network and System Sciences, 9(4), 67-76.

Roungrong, P., Jiravarapong, B., Manyum, W., Somyaron, W., Muendet, S., \& Srisurat, S. (2014). Educational technology vs Thai teachers in 21 st century. Panyapiwat Journal, 5, 195-207

Promboon, S., Sumonta, P., Pornsima, O., \& Orapan, P. (1997). participatory learning theory. Journal of Education Studies, 26(1),23-34.

Jaleel, S., \& Anuroofa O.M. (2017). A study on the relationship between self directed learning and achievement in information technology of students at secondary level. Universal Journal of Educational Research, 5(10), 1849-1852.

Shelton, B. E., \& Hedley, N. R. (2002). Using augmented reality for teaching earth-sun relationship to undergraduate geography students. The First IEEE International Augmented Reality Toolkit Workshop, 1-8.

Shiue, Y. M., Hsu, Y. C., Sheng, M. H., \& Lan, C. H. (2019). Impact of an augmented reality system on students' learning performance for a health education course. International Journal of Management, Economics and Social Sciences, 8(3), 195 - 204.

Spiro, R. J., Feltovich, P. J., Jacobson, M. J., \& Coulson, R. L. (1991). Cognitive flexibility constructionism, and hypertext: Random access instruction for advanced knowledge acquisition in ill-structured domains. Educational Technology, 31(5), 24-33.

Yeom, S. J. (2011). Augmented reality for learning anatomy. Proceedings of Changing Demands, Changing Directions, 1377-1383. 